\title{
Visual Analog Pain Scale
}

National Cancer Institute

\section{Source}

National Cancer Institute. Visual Analog Pain Scale. NCI Thesaurus. Code C21120.

A pain scale marked off like a ruler from 0 to 10 on which the patient marks the current level of pain experienced. 